УДК [82.09:7.01]"1941-1945"

\title{
Т.В. Данилович
}

\section{РУССКАЯ ЛИТЕРАТУРНАЯ КРИТИКА 1941-1945 ГГ. В КОНТЕКСТЕ КОНЦЕПЦИИ «ЧИСТОГО ИСКУССТВА»}

В статье рассматриваются эстетические взгляды представителей советской литературной критики периода Великой Отечественной войны в соотнесении с установками приверженцев концепции чистого искусства. В этом аспекте осмысливаются как доминирующие тенденции в критике обозначенного периода, так и не получившие в ней широкого распространения. Выявляется характер рецепции критиками военного времени творческого наследия сторонников «искусства для искусства», разрабатывавших свои идеи в XIX столетии. Доказывается, что, несмотря на преобладание категоричных заявлений об абсолютной неприемлемости для советского писателя концепции чистого искусства в качестве вектора творческой деятельности и утверждений в защиту утилитарных установок, ряд принципов «искусства для искусства» все же актуализируется критиками военного периода, что однако осуществляется без привязки к этой концепции и ссылки на суждения ее авторитетных выразителей.

Ключевые слова: чистое искусство, «вечные» темы, воспитательная роль литературы, идейность, писательгражданин, публицистическая критика.

DOI: $10.35634 / 2412-9534-2021-31-2-335-341$

В русской литературной критике 1920 -х - 1930-х гг. концепция чистого искусства нередко была предметом активного обсуждения, поскольку эстетические установки советской литературы формировались и оттачивались во многом в отталкивании от идей приверженцев «искусства для искусства». В 1941-1945 гг. интерес к этой теме снижается. Однако в военное время, когда сокращается тираж и объем журналов, она все же не перестает быть объектом внимания, что свидетельствует о ее важности для осмысления истории и тенденций развития литературы, утверждения эстетических ориентиров советских писателей.

В дни войны, как и в довоенные годы, концепция чистого искусства продолжает осмысливаться в качестве чужеродного для русской культуры явления, всегда занимавшего в ней периферийное место. В противоположность идее «искусства для искусства» сохраняет актуальность принцип партийности искусства и отмечается его позитивное влияние на развитие советской литературы [2; 23 и др.].

Если в 1920-е - 1930-е гг. противники чистого искусства объясняют неудобоваримость этой концепции для советского художника необходимостью его участия в строительстве нового мира, то в военное время акцент на установках, противоположных эстетическим ориентирам сторонников чистого искусства, оказывается обусловлен прежде всего осознанием происходящего в стране как ситуации, требующей всеобщей мобилизации ради приближения победы. Советская литература периода Великой Отечественной войны, говоря словами критика А. Мясникова, превращается в «воюющую литературу» [13, с. 136].

Отстаивая важность активного включения искусства в борьбу с фашизмом, критики этого периода в отличие от культивируемого приверженцами чистого искусства образа свободного художника видят литератора «пламенным, истым гражданином своего отечества» [23, с. 195]. Ближе к концу войны установка на гражданское служение искусства приобретает новые смысловые обертоны: наряду с мыслью о необходимости вклада писателей в победу отмечается и значимость их участия в патриотическом воспитании будущих поколений советских граждан [5; 11 и др.]. Идея необходимости сознательной, целенаправленной творческой установки писателя на решение общественных проблем оказывается доминирующей, а суждения о непреднамеренной пользе литературы звучат скорее как исключение из правила. Приведем в пример точку зрения К. Федина, который в мемуарной книге «Горький среди нас» отмечает: «Искусство тенденциозно. Это значит, что из любого произведения искусства с неизбежностью вытекает тенденция. Но художник не тенденциозен. Это значит, что он свободен от намерения что-либо насильственно придать своему искусству» [22, с. 129-130]. Мысли К. Федина звучат в унисон с суждениями сторонников чистого искусства. Например, у А. Дружинина, защищавшего теорию «независимого и свободного творчества», читаем: «Гомер не учит нас ни- 
чему - а чему нельзя выучиться из Гомера?» [7, с. 151]. Писатель, согласно А. Дружинину, «не дает уроков обществу, или, если дает их, то дает бессознательно» [7, с. 147]. На родственность точки зрения К. Федина и приверженцев «искусства для искусства» указывает М. Розенталь, в статье которого «Об идейности и тенденциозности искусства» отмечается, что вопрос о тенденциозной природе искусства был составляющей дискуссий представителей радикально-демократической и артистической школы критики. Победителями автор признает первых, утверждая мысль о прогрессивности их эстетических идей: «Русская революционная критика - критика Белинского, Чернышевского, Добролюбова, - формулируя основные законы искусства, борясь за подлинно научную эстетику, опиралась прежде всего на опыт русского искусства. В частности, прекрасно разработанный и всесторонне обоснованный ею эстетический принцип идейности и тенденциозности искусства был прямым выражением лучших сторон этого искусства» [18, с. 152]. В качестве аргумента в пользу идей радикальнодемократической критики М. Розенталь ссылается на авторитет русской классической литературы. Апелляция к ней становится распространенным явлением в литературной критике 1941-1945 гг.

В дни войны учительская традиция русской литературы преподносится в качестве образца для подражания и аргумента в пользу активной гражданской позиции художника $[6 ; 8 ; 23 ; 15$ и др.]. В противоположность этому сторонники чистого искусства нередко считали ориентир отечественной литературы на учительство временным явлением, которое необходимо преодолеть. Так, Эллис в статье «Что такое литература?» (1907), соглашаясь с суждениями об общественном характере русской литературы, возражает тем, кто рассматривает это как ее положительное качество. Он считает дидактизм в искусстве следствием несовершенства политического устройства страны, нуждающейся во вмешательстве литературы в общественную жизнь для разрешения злободневных проблем. Критики же периода Великой Отечественной войны характеризуют учительство как «высокую миссию русского писателя» [15, с. 247], неоспоримое достоинство и национальную особенность отечественной литературы. Согласно М. Добрынину, русская литература «никогда не замыкалась в сфере чисто эстетических интересов, но всегда была кафедрой, с которой раздавалось учительное слово» [6, с. 139]. По словам Н. Калитина, пафос общественного служения нередко граничил у русского писателя «с прямою жертвенностью», и поэтому литература играла активную роль «в борьбе за освобождение народных масс, за наиболее полное развитие всех возможностей и сил народа» [8, с. 140]. По убеждению Т. Мотылевой русская литература, которая «настойчиво утверждает неразрывность связи эстетики с этикой, придает огромное значение активной воспитывающей функции искусства» [12, с. 267], развивается в верном направлении в отличие от западного искусства, оказавшегося на рубеже XIX$\mathrm{XX}$ вв. в состоянии кризиса из-за «разрыва поэзии и жизни, красоты и правды» [12, с. 269].

Тема учительства русской литературы в критике периода Великой Отечественной войны рассматривается и в отношении советских писателей 1920-х-1930-х гг. Ф. Гладков отмечает, что советская литература наследует и развивает «высокую пропагандистскую роль» русской классики, «с честью несет знамя с л у ж е н и я народу» [5, с. 149]. А. Лейтес указывает на то, что активная гражданская позиция писателей в дни войны оказалась подготовлена предыдущим опытом деятельного участия советской литературы в разрешении злободневных вопросов. «Не случайно мы в течение многих лет воспитывались в традициях Горького и Маяковского», - пишет критик [10, с. 241].

Если в дни войны упоминания о дидактическом характере русской литературы встречаются достаточно часто, то искания ее ключевых фигур в направлении чистого искусства либо игнорируются, либо преподносятся как несущественный эпизод их творческой биографии. В противоположность утверждениям сторонников чистого искусства о Пушкине как чистом художнике в литературной критике военного времени пушкинское творчество осмысливается исключительно как путь писателягражданина. Например, В. Перцов, называя Пушкина «великим гражданским поэтом», противоречащие этому облику эстетические идеи, выраженные в стихотворении «Поэт и толпа», объясняет тем, что Пушкин «под влиянием неблагоприятно складывавшихся для него обстоятельств вступал в спор с самим собой, оправдывая “чистое искусство”» [15, с. 248]. Согласно критику, сторонники чистого искусства, апеллировавшие к Пушкину, «стремились в своих корыстных общественно-реакционных целях использовать “сладкие звуки” пушкинской музы» [15, с. 248]. Подобные утверждения о лицемерности проповедников чистого искусства, прикрывающихся этой теорией ради защиты собственных политических интересов, оказываются распространенным мотивом в советской литературной критике.

Попытки «обелить» репутацию знакового для советского общества писателя, который проявлял интерес к идеям чистого искусства, предпринимались и в отношении Маяковского. В посвященных 
Русская литературная критика 1941-1945 гг. в контексте концепции...

ему работах нередко умалялось влияние на поэта эстетических принципов кубофутуризма, ряд которых был подчинен реализации идеи чистого искусства. Пример такого подхода - суждение И. Сельвинского о том, что поэт лишь теоретически поддерживал кубофутуристические формальные эксперименты, а на практике погружался в злободневные общественные проблемы [19]. Распространенным оказывается упоминание о противодействии поэта чистому искусству в послереволюционный период творчества. «Под знаменем Маяковского росла и мужала советская поэзия 20-х-30-х годов, поднявшая свой голос против “старья лирозвонов", за искусство, которое способно "выволочь республику из грязи”», - пишет Л. Поляк [17, с. 293]. Критик отмечает нацеленность поэта на освещение актуальных социальных проблем в противоположность лирикам, стремившимся к поэтизации «вечных» тем. Противопоставление этих тематических линий в литературе традиционно является важнейшей составляющей полемики апологетов и противников чистого искусства.

Относительно права художника на обращение к вневременным ценностям в литературной критике 1941-1945 гг. высказываются разные точки зрения. Один полюс - категоричные заявления о необходимости в дни войны создавать только злободневные произведения. Например, критик В. Щербина характеризует путь писателя-гражданина как единственно возможный эстетический ориентир, когда «никто из литераторов не вправе забывать о том, чем живет весь советский народ, отдающий все силы делу разгрома врага» [23, с. 196]. Литературную деятельность, отстраненную от проблем действительности, критик не признает: «Не могут служить оправданием ссылки на так называемую “особенность писательской манеры”, “особый круг тем” и т. д. и т. п.» [23, с. 196]. Другой полюс восприятия «вечных» тем в искусстве - защита права художника на поэтизацию вневременных ценностей, попытка доказать их уместность в советской литературе в целом, и в литературе военного периода в частности. При этом отстаивается идея включения «вечных» тем в арсенал художника наравне со злободневными. Подобный подход встречается и у представителей такой модели чистого искусства, адепты которой не выступают за ограничение творчества определенным кругом тем, видят реализацию идеи чистоты литературы в неангажированности творческой деятельности. Однако среди приверженцев чистого искусства есть и те, кто воспринимает «вечные» темы как единственно возможный предмет творчества, видит путь реализации идеи автономии искусства в творческом дистанцировании от злободневных тем. В критике 1941-1945 гг. об изоляции искусства от общественно-политической тематики речи не ведется.

Доминировавшей в 1920-е-1930-е гг. эстетической установке на отказ от воплощения вневременных вопросов в период Великой Отечественной войны даются разные оценки. Одни критики считают такой ориентир ошибочным, другие - оправданным в ту эпоху. Например, Ан. Тарасенков характеризует табу на «вечные» темы как незрелое восприятие искусства, которое осталось в прошлом: «Мы давно выросли из пеленок своего ребячества, и воин, кидающий гранату в немецкий блиндаж, знает и ощущает необходимость песни, лирики, одухотворяющей любви к облакам или кленам нисколько не хуже и не меньше, чем ученый книгочий, половину жизни проведшей за столом Ленинской библиотеки» [21, с. 137]. Иной точки зрения придерживается Л. Поляк: «В суровые дни гражданской войны, в трудные годы начинавшегося строительства существовал не писанный, никем не сформулированный, но всеми молчаливо признанный поэтический устав, накладывавший свое veto на интимно-лирические темы. Это была вполне законная реакция советских поэтов, противопоставивших свое революционное творчество камерной, домашней лирике декадентов, их творческой замкнутости, нарочитой отдаленности от мира. < .. > Чистая лирика в эти годы, в годы рождения и укрепления молодой республики, зачастую свидетельствовала о трещине в мироощущении поэта, о его социальной неполноценности» $[17$, с. 293]. В данном случае транслируется мысль о ситуативной уместности определенных тем в искусстве, что перекликается с суждением Достоевского о лиссабонском землетрясении как примере трагических обстоятельств, в которых недопустимо отстранение поэта от злобы дня, обращение поэта к традициям чистого искусства.

Аргументация, используемая в литературной критике периода войны для реабилитации «вечных» тем, разнообразна. В арсенале используемых доводов есть и те, которые близки аргументам сторонников чистого искусства, и те, которые разнятся с аргументацией последних. Например, Ан. Тарасенков, отстаивая право художника на «вечные» темы, апеллирует к их необходимости в любые времена и важности тематической многообразности искусства, которому в равной степени «нужны и Маяковский с его волевым вмешательством в социальные судьбы мира, и Пастернак с его дроздовой флейтой» [21, с. 137]. Аргументы критика схожи с образом мыслей В. Брюсова, считавше- 
го «вечные» темы всегда своевременными, и утверждавшего, что гражданская линия может быть лишь одним из ответвлений искусства, но не его единственным объектом: «Требовать, чтобы все искусство служило общественным движениям, все равно что требовать, чтобы вся ткацкая промышленность только и делала, что приготовляла материю для красных флагов» [4, с. 105].

В пользу вневременных тем в критике 1941-1945 гг. используется и суждение о трансформации личного в общественное под влиянием военной действительности. «В советской поэзии и критике исчезли так недавно казавшиеся существенными вопросы о том, имеет или не имеет право поэт на "чистую”, “свою”, “интимную” лирику. Об этом уже не нужно говорить и спорить, ибо “своим”, “интимным”, “личным” стало общенародное. <..> Все самое “интимное” - любовь, дружба, счастье, - поновому освещенное пламенем великой битвы, приобрело высокую значимость общественного», - пишет 3. Кедрина [9, с. 91]. Защищая право на «вечные» темы, к личному в русской критике сер. XIX в. апеллировал В. Боткин, отмечая: «Прежде всяких требований современности существует личное я, существует это сердие, этот человек, имеющий неотъемлемое право быть самим собою, то есть чувствовать, думать, не справляясь с мимолетными требованиями современности» [3, с. 210]. Если В. Боткин противопоставляет личное и общественное, отстаивая право на обращение художника к вневременным темам, то 3. Кедрина пишет о проникновении общественного в личное под влиянием суровых реалий войны, актуальности освоения личных тем для решения важнейших проблем современности.

В тандеме с осмыслением вопроса о поэтизации вечных ценностей в искусстве нередко обсуждается и тема долговременности общественного бытия художественных произведений. Для сторонников чистого искусства важнейшим показателем качества произведения является его востребованность потомками. Приверженность злободневным темам они нередко характеризуют как выбор, ведущий к быстрому забвению писателя. «Незыблемо и твердо стоят поэты, чтители искусства чистого, голос их раздается из столетия в столетие, между тем как голоса дидактиков (часто благородные и сильные голоса) умирают, едва прокричавши кое-что, и погружаются в пучину полного забвения. $<\ldots>$ То, что сегодня было ново, смело и плодотворно - завтра старо и неприменимо, и, что еще грустнее, не нужно обществу!» - утверждает А. Дружинин [7, с. 150]. В литературной критике 19411945 гг. по вопросу о долговечности литературных творений высказываются разные точки зрения. Одна из них - необходимость в дни войны пренебречь заботой о вечности создаваемых произведений, а беспокоиться только об их вкладе в победу. Так, позиционируя себя как художника, который всегда отстаивал интересы литературы, И. Эренбург считает необходимым в военное время отдать приоритет защите интересов общества: «Снова и снова мне хочется повторить: не книги мы сейчас должны защищать - читателей: они, наши читатели, защищают Россию - и землю, и язык, и мысль» [24, с. 238]. Другая точка зрения - утверждение значимости критерия долговечности художественных произведений и убежденность в том, что созданное на злобу дня способно пережить свое время и быть востребованным будущими поколениями. «Лучшее, то есть нужнейшее из того, что создаем мы сегодня в искусстве, сделано не на время, а навсегда», - отмечает В. Перцов [16, с. 196]. Звучит мысль о социальной проблематике как оптимальном выборе для творческой личности, задумывающейся о долговременности своих творений. Так, П. Скосырев утверждает: «Великие поэты никогда не бежали от современности. Они только потому и стали “вечными”, что всю свою огромную поэтическую силу и страсть отдавали тому, что было для них злободневным» [20, с. 238]. Эти суждения контрастируют с утверждениями адептов чистого искусства о том, что долголетие суждено лишь произведениям, поднимающим «вечные» темы.

В поле зрения ряда критиков оказывается и позиция творческого молчания художника в дни войны. Этот выбор получает однозначно негативную оценку со стороны советских критиков. Например, А. Аникст, рассматривая дистанцирование художника как распространенное явление в западном мире, с симпатией говорит о тех, кто выбрал для себя путь деятельного участия в событиях эпохи. «Когда фашистская Германия зажгла пожар второй мировой войны, - отмечает критик, - Пристли не ушел в “башню из слоновой кости”, как это сделали многие писатели Запада, ошеломленные катастрофой и решившие переждать бурю. Он занял место в рядах борцов» [1, с. 212]. О намерении некоторых английских поэтов «положить свои стихи в сейф до окончания войны» И. Эренбург пишет: «Я не думаю, что музы на поле боя молчат. <..> Идея английских поэтов мне кажется не столь безнравственной, сколь беспомощной. Кто будет защищать их сочетания слов?» [24, с. 236]. Критик рассуждает об отсутствии у писателей творческого отклика на происходящее в обществе как проявление безучастия к тому, чем озабочены их сограждане. В отличие от такой точки зрения представители чистого 
Русская литературная критика 1941-1945 гг. в контексте концепции...

искусства не считают, что свой гражданский долг литератор должен выполнять посредством собственной творческой деятельности. «Может быть в иные дни поэт, как гражданин, обязан идти на баррикады, но он не обязан рассказывать об этом в особой поэме»,- отмечает В. Брюсов [4, с. 104].

Утилитарный взгляд на литературное творчество в критике периода Великой Отечественной войны проявляется и при осмыслении образа советского читателя. В противоположность утверждению сторонников чистого искусства о необходимости «незаинтересованного» отношения к художественным произведениям в статьях 1941-1945 гг. неоднократно указывается на то, что в дни войны литература стала восприниматься как источник знаний и руководство к действию. Советские читатели, убежден И. Эренбург, с помощью книги пытаются найти ответы «на сложные и мучительные вопросы», «хотят понять себя, свое время» [25, с. 116]. При этом прагматизм читательских запросов признается критиком обоснованным, что в корне отличается от свойственного многим защитникам чистого искусства пренебрежения требованиями «толпы», отрицания ее права диктовать художнику какие-либо условия. И. Эренбург упрекает себя и писателей-современников в отсутствии должного внимания к потребностям читателя: «Мы недостаточно думали об этике, а вне этики нет искусства» [25, с. 116].

В период Великой Отечественной войны утилитарные тенденции преобладают и в выборе подхода к анализу художественных произведений, в формировании критериев их оценки критикой. Распространенными оказываются суждения о приоритетности идейно-содержательного наполнения художественного текста. Иллюстрацией такого взгляда на искусство могут служить следующие слова А. Мясникова: «Значение и сила литературных произведений в наше время измеряется их значением для священной войны» [13, с. 143]. Высшая оценка литературы в дни войны, с точки зрения критика, «вой врагов и восхищение друзей» [13, с. 144]. Схожих взглядов придерживается П. Павленко. Считая, что критиковать любое произведение «должно, лишь стоя на позициях общенародного интереса, а им в данный момент являются вопросы войны и победы», писатель уверяет, что только при таких условиях критик «приобретет свободу суждений и даст верную оценку произведению», которая «будет в то же время и эстетической оценкой» [14, с. 109]. В отличие от представителей радикально-демократической критики XIX в., которые, оценивая общественную значимость литературного произведения, подчеркивали, что оно может не отвечать эстетическим требованиям, П. Павленко рассматривает злободневность как критерий художественности творений искусства.

В качестве образца для подражания в критике военной поры нередко преподносится деятельность Белинского, Чернышевского и его соратников, которым «любая книжка, любой журнал и брошюра были поводом для философско-публицистических выступлений» [5, с. 153], а представители артистической школы критики характеризуются как защитники реакционной теории, успешно развенчанной представителями радикально-демократического лагеря, создавшими эстетическое учение, которое «выдержало все испытания времени» [23, с. 196].

Несмотря на преобладание негативного отношения к попыткам «анализировать “изящную словесность” с точки зрения эстетики» [5, с. 151], в критике 1941-1945 гг. раздавались и голоса в защиту качества литературы военного времени. Выразительный пример такой позиции - суждения В. Перцова о том, что в избытке создается «литературная продукция поверхностная, а то и прямо халтурная», что многим «даже квалифицированным произведениям» присуща «голая “агитность", поспешное писание «на тему», пусть благородную, но не прошедшую еще сквозь сердце, нервы, все существо художника» $[15$, с. 247]. Такой подход созвучен обеспокоенности апологетов чистого искусства художественным уровнем литературных произведений середины X1X в.

Тенденции развития русской литературной критики 1941-1945 гг. свидетельствуют о том, что в этот период сохраняется актуальность большинства эстетических установок и идеалов советской критики 1920-1930-х гг., которые чужеродны приверженцам чистого искусства: ориентир на решение в литературе воспитательных задач, принцип партийности искусства, нацеленность на описание злободневных тем, культ писателя-гражданина, первостепенность идейно-содержательного уровня художественного текста, идеологический критерий оценки художественных явлений. При этом, несмотря на отсутствие последовательных защитников чистого искусства и нацеленности на актуализацию его идеи, в литературной критике периода войны прослеживаются попытки (зачастую имеющие единичный характер) утвердить ряд эстетических установок, первостепенных для сторонников этой концепции: непреднамеренность общественной пользы произведений искусства, бестенденциозность творчества, вневременная актуальность «вечных» тем, эстетический критерий оценки художественных явлений. 


\section{СПИСОК ИСТОЧНИКОВ И ЛИТЕРАТУРЫ}

1. Аникст А. Социальный роман о современной Англии // Знамя. 1945. № 1. С. 212-218.

2. Аникст Наша литература // Знамя. 1945. № 4. С. 118-124.

3. Боткин В.П. Литературная критика; Публицистика; Письма. М.: Сов. Россия, 1984. 320 с.

4. Брюсов В.Я. Сочинения. В 2-х т. Т. 2. Статьи и рецензии 1893-1924; Из книги «Далекие и близкие»; Мiscellanea. М.: Худож. лит., 1987. 575 с.

5. Гладков Ф. Заметки писателя // Новый мир. 1945. № 4. С. 148-155.

6. Добрынин М. Идея патриотизма в русской литературе // Новый мир. 1943. № 12. С. 139-141.

7. Дружинин А.В. Литературная критика. М.: Сов. Россия, 1983. 384 с.

8. Калитин Н.В. Маяковский и традиции русской литературы // Новый мир. 1943. № 7/8. С. 136-140.

9. Кедрина 3. Испытание огнем // Октябрь. 1942. № 12. С. 85-93.

10. Лейтес А. Новые стихи Алексея Суркова // Новый мир. 1942. № 3/4. С. 241-245.

11. Маршак С. Я. О детской литературе наших дней // Новый мир. 1944. № 3. С. 149-153.

12. Мотылева Т. Русская литература и Запад // Знамя. 1943. № 11/12. С. 257-269.

13. Мясников А. Литература и война // Октябрь. 1942. № 11. С. 136-144.

14. Павленко П. «Фронт» // Октябрь. 1942. № 10. С. 109-111.

15. Перцов В. Маяковский и русская муза // Октябрь. 1945. № 5/6. С. 245-253.

16. Перцов В. Писатель и его герой в дни войны // Октябрь. 1943. № 6/7. С. 183-197.

17. Поляк Л. О «лирическом эпосе» Великой Отечественной войны // Знамя. 1943. № 9/10. С. $292-299$.

18. Розенталь М. Об идейности и тенденциозности искусства // Октябрь. 1945. № 1/2. С. 152-161.

19. Сельвинский И. О книге В. Катаняна «Маяковский» // Знамя. 1945. № 4. С. 125-135.

20. Скосырев П. Самед Вургун // Новый мир. 1942. № 3/4. С. 236-240.

21. Тарасенков Ан. Новые стихи Бориса Пастернака // Знамя. 1945. № 4. С. 136-138

22. Федин К. Горький среди нас: Картины литературной жизни. В 2 ч. Ч. 2: 1921-1928. М.: Гос. изд-во худож. лит., 1944. 171 с.

23. Щербина В. Ленин и традиции русской литературы // Новый мир. 1944. № 1/2. С. 190-214.

24. Эренбург И. В боевом порядке // Знамя. 1943. № 5/6. С. 235-238.

25. Эренбург И. Долг писателя // Новый мир. 1943. № 9. С. 111-116.

Поступила в редакцию 18.08.2020

Данилович Татьяна Валерьевна, кандидат филологических наук, доцент

кафедры белорусской и зарубежной литературы

ГУО «Белорусский государственный педагогический университет имени Максима Танка»

220030, Беларусь, г. Минск, ул. Советская, 18

E-mail: tanya.tada@mail.ru

\section{T.V. Danilovich \\ RUSSIAN LITERARY CRITICISM FROM 1941 TO 1945 WITHIN THE CONTEXT OF CONCEPT OF "PURE ART"}

DOI: $10.35634 / 2412-9534-2021-31-2-335-341$

The aesthetic views of representatives of Soviet literary criticism during the Great patriotic war, in relation to the orientation of the supporters of the concept of pure art, are discussed in the article. In this aspect both dominant and not so widely spread tendencies in criticism of the designated period are being comprehended. The character of reception of artistic heritage, which belongs to the supporters of the concept of pure art in the Russian culture of $19^{\text {th }}$ century, in the criticism from 1941 to 1945 is being identified. Despite the prevalence of categorical statements which consider the concept of "art for art's sake" as a vector of creative activity to be absolutely unacceptable for a Soviet writer and statements in defense of utilitarian attitudes, it is being proved that a number of principles of "art for art's sake" are still being mainstreamed by the critics of the period of war. This, however, is being carried out without reference to this concept or to the judgments of its authoritative spokesmen.

Keywords: pure art, themes of eternity, educational role of literature, ideological content, citizen writer, journalistic criticism. 


\section{REFERENCES}

1. Anikst A. Socialnyj roman o sovremennoj Anglii [Social novel about modern England]. Znamya [The Banner], 1945, no. 1, pp. 212-218. (In Russian).

2. Anikst A. Nasha literatura [Our literature]. Znamya [The Banner], 1945, no. 4, pp. 118-124 (In Russian).

3. Botkin V. Literaturnaya kritika; Publicistika; Pis'ma [Literary criticism; Journalism; Letters]. M.: Sovetskaya Rossiya [Moscow.: Soviet Russia], 1984. 320 p. (In Russian).

4. Bryusov V. Ya. Sochineniya. V 2-h t. T. 2. Stat'i i recenzii 1893-1924; Iz knigi «Dalekie i blizkie»; Miscellanea. [Works, 2 vol. set, vol. 2: Articles and reviews 1893-1924; From the book «Distant and Close»; Miscellanea]. M.: Hudozhestvennaya literatura [Moskow: Fiction], 1987, 575 p. (In Russian).

5. Gladkov F. Zametki pisatelya [Writer Notes]. Novy’j mir [New World], 1945, no. 4, pp. 148-155. (In Russian).

6. Dobry`nin M. Ideya patriotizma v russkoj literature [The idea of patriotism in Russian literature]. Novy`j mir [New World], 1943, no. 12, pp. 139-141. (In Russian).

7. Druzhinin A. Literaturnaya kritika [Literary criticism]. M.: Sovetskaya Rossiya [Moscow: Soviet Russia], 1983, 384 p. (In Russian).

8. Kalitin N.V. V. Mayakovskij i tradicii russkoj literatury [V. Mayakovsky and the traditions of Russian literature]. Novy`j mir [New World], 1943, no. 7/8, pp. 136-140. (In Russian).

9. Kedrina Z. Ispytanie ognem [Test of fire]. Oktyabr` [October], 1942, no. 12, pp. 85-93. (In Russian).

10. Lejtes A. Novye stihi Alekseya Surkova [New poems by Alexei Surkov]. Novy`j mir [New World], 1942, no. 3/4, pp. 241-245. (In Russian).

11. Marshak S. Ya. O detskoj literature nashih dnej [About children's literature of our days]. Novy`j mir [New World], 1944, no. 3, pp. 149-153. (In Russian).

12. Moty leva T. Russkaya literatura i Zapad [Russian literature and the West]. Znamya [The Banner], 1943, no. 11/12, pp. 257-269. (In Russian).

13. Myasnikov A. Literatura i vojna [Literature and War]. Oktyabr` [October], 1942, no. 11, pp. 136-144. (In Russian).

14. Pavlenko P. «Front» [«Front»]. Oktyabr` [October], 1942, no. 10, pp. 109-111. (In Russian).

15. Perczov V. Mayakovskij i russkaya muza [Mayakovsky and the Russian Muse]. Oktyabr` [October], 1945, no. 5/6, pp. 245-253. (In Russian).

16. Perczov V. Pisatel' i ego geroj v dni vojny [The writer and his hero during the days of the war]. Oktyabr' [October], 1943, no. 6/7, pp. 183-197. (In Russian).

17. Polyak L. O «liricheskom epose» Velikoj Otechestvennoj vojny [On the «lyric epic» of Great Patriotic War] Znamya [The Banner], 1943, no. 9/10, pp. 292-299. (In Russian).

18. Rozental' $\mathrm{M}$. Ob idejnosti i tendencioznosti iskusstva [On the ideological content and tendentiousness of art]. Oktyabr` [October], 1945, no. 1/2, pp. 152-161. (In Russian).

19. Sel'vinskij I. O knige V. Katanyana «Mayakovskij» [About V. Katanyan's book «Mayakovsky»]. Znamya [The Banner], 1945, no. 4, pp. 125-135. (In Russian).

20. Skosy`rev P. Samed Vurgun [Samed Vurgun]. Novy`j mir [New world], 1942, no. 3/4, pp. 236-240. (In Russian).

21. Tarasenkov An. Novye stihi Borisa Pasternaka [New poems by Boris Pasternak]. Znamya [The Banner], 1945, no. 4, pp. 136-138. (In Russian).

22. Fedin K. Gor`kij sredi nas: Kartiny` literaturnoj zhizni. V 2-h ch. Ch. 2: 1921-1928 [Gorky among us: Pictures of literary life. In 2 parts. Part 2: 1921-1928], M.: Gosudarstvennoe izdatel'stvo hudozhestvennoj literatury [Moscow, State Press of Fiction]. 1944, 171 p. (In Russian).

23. Shherbina V. Lenin i tradicii russkoj literatury [Lenin and the traditions of Russian literature]. Novy $\mathrm{j}$ mir [New World], 1944, no. 1/2, pp. 190-214. (In Russian).

24. E`renburg I. V boevom poryadke [In battle order]. Znamya [The Banner], 1943, no. 5/6, pp. 235-238. (In Russian).

25. E’renburg I. Dolg pisatelya [Duty of writer]. Novy`j mir [New World], 1943, no. 9, pp. 111-116. (In Russian).

Received 18.08.2020

Danilovich T.V., Candidate of Philology, Associate Professor at Department of Belarusian and Foreign Literature Belarusian State Pedagogical University named after Maxim Tank

Sovetskaya st., 18, Minsk, Belarus, 220030

E-mail: tanya.tada@mail.ru 